\title{
Pricing To maximize SMR via optimal control theory
}

\author{
sara Dadras ${ }^{1}$ and mahmoud mahmoudi ${ }^{1}$ \\ ${ }^{1}$ University of Qom
}

June 19, 2020

\begin{abstract}
In this paper, the porpuse is to determine an optimal premium in order to increase the insurer's SMR using a control model. For this purpose, First, a stochastic dynamic model is introduced to describe the process of receiving premium and paying claims. Then, the premium variable is introduced as the problem control variable. Next, In order to increase SMR and control the premium, an appropriate objective function is defined for control variables and state variables. In the end, after deterministing and discreting the model, the optimal control problem by using particle swarm is solved.
\end{abstract}

\section{Hosted file}

Pricing To maximize SMR via optimal control-with name.pdf available at https://authorea.com/ users/335189/articles/461046-pricing-to-maximize-smr-via-optimal-control-theory 

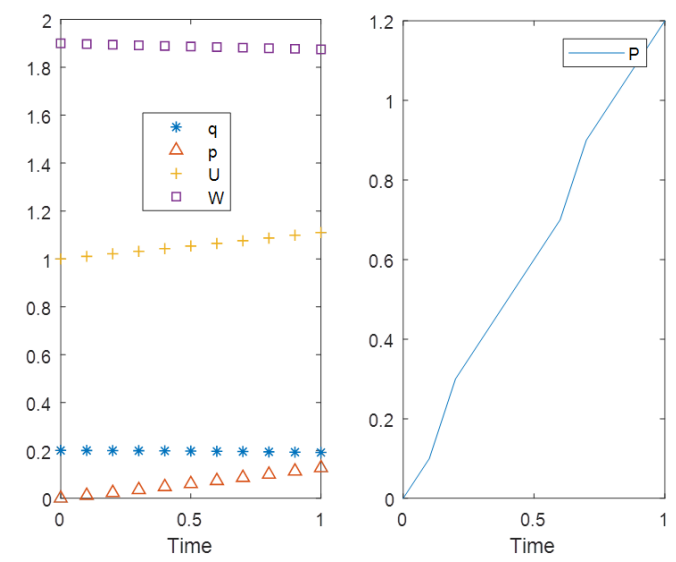

Figure.1 